\title{
The Electronic, Magnetic and Optical Properties of Ba2MUO6 Compounds With (M=Ni, Co, Cd and Zn): DFT Calculation
}

\section{Abdelmajid Kadiri ( $\sim$ kadiri.abdelmajid@gmail.com )}

Université Mohammed V de Rabat Faculté des Sciences: Universite Mohammed V de Rabat Faculte des Sciences

\section{Mestapha Arejdal}

Mohammed V University of Rabat

\section{Abderrahman Abbassi}

Polydisciplinary Faculty of Beni Mellal, Sultan Moulay Slimane University

\section{Research Article}

Keywords: The Double Perovskites Ba2MUO6, Electronic Magnetic and Optical proprieties, Density Functional Theory (DFT), Generalized Gradient Approximation (GGA)

Posted Date: February 15th, 2021

DOI: https://doi.org/10.21203/rs.3.rs-221491/v1

License: (c) (i) This work is licensed under a Creative Commons Attribution 4.0 International License. Read Full License

Version of Record: A version of this preprint was published at Optical and Quantum Electronics on July 14th, 2021. See the published version at https://doi.org/10.1007/s11082-021-03058-9. 


\title{
The electronic, magnetic and optical properties of $\mathrm{Ba}_{2} \mathrm{MUO}_{6}$ compounds with $(\mathrm{M}=\mathrm{Ni}, \mathrm{Co}, \mathrm{Cd}$ and $\mathrm{Zn})$ : DFT calculation
}

\author{
M. AREJDAL ${ }^{1}$, A. ABBASSI ${ }^{2}$ and A. KADIRI ${ }^{1}$ \\ ${ }^{1}$ Laboratory of Condensed Matter and Interdisciplinary Sciences (LaMCScI), Faculty of Sciences, \\ Mohammed V University, Av. Ibn Batouta,B.P. 1014, Rabat, Morocco. \\ ${ }^{2}$ Polydisciplinary Faculty of Beni Mellal, Sultan Moulay Slimane University, Mghila BP: 592 Beni Mellal \\ Morocco
}

\begin{abstract}
In this present paper, the electronic, magnetic and optical properties of the double Perovskites $\mathrm{Ba}_{2} \mathbf{M U O}_{6}$ with $(\mathbf{M}=\mathrm{Ni}, \mathrm{Co}, \mathrm{Cd}$ and $\mathrm{Zn})$ are investigated in the framework of the Generalized Gradient Approximation (GGA), employing the Full Potential-Linearized Augmented Plane Wave (FP-LAPW) method as implemented in the Wien2K package. The only method used to study these three types of the properties of these compounds is Density Functional Theory (DFT) approach. Thanks to this method, several of the detailed results related to the three studied properties of these compounds are determined; specifically, the optimization of parameters of structures, the band structures, the electronic densities of states (DOS), reflectivity, transmittance and absorbance. Finally, the comparison between these results obtained in this theoretical study and the experimental values makes it clear that they are virtually in good agreement with each other.
\end{abstract}

Keywords: The Double Perovskites $\mathrm{Ba}_{2} \mathrm{MUO}_{6}$; Electronic Magnetic and Optical proprieties; Density Functional Theory (DFT); Generalized Gradient Approximation (GGA).

*) Corresponding author: arejdal.achdad@gmail.com 


\section{1- Introduction}

Since the last two decades or so of the twentieth millennium, great efforts have been made and still by researchers specialized in the different scientific fields, particularly by physicists from all over the world, aiming to explore and discover the secrets of the digital world as a gateway towards meeting our dire needs in the world of the new information technologies and communications through inventing as, for instance, more powerful storage means and more sophisticated processing systems. Up to now, the breakthroughs the scientists and researchers have made in the two previous examples are thanks to both the utilization of the materials with original features and the advent of the new science so-called spin electronics or spintronics [1]. This latter, in turn, has made the job so much easier for the researchers to meet the requirements of the new information technologies through designing and creating more developed storage means, in particular. The impact of this new science is far-reaching in the sense that it has induced huge changes in the field concerned. Indeed, materials with high spin polarization, as the principal basis of this field, have played the biggest part in making this field evolve and flourish. At this point, it seems illuminating to mention that this new science has directed or steered great deal of the research conducted on the electron spin.

In this respect, the half-metals, whose properties are optical and magnetic, are supposed to hugely contribute into the development of this field, for they have conduction band totally polarized by spin below their Curie temperature. These semi-metals, which are among the materials this domain drastically and terribly entails, stem from the family of crystalline oxides. This family named the double Perovskite whose general formula is: $\mathbf{A}_{2} \mathbf{B} \mathbf{B}^{\mathbf{}} \mathbf{O}_{6}$ where $\mathbf{A}$ denotes a large electropositive cation; $\mathbf{B}$ and $\mathbf{B}$ ' are small transition metals; and $\mathbf{O}$ refers to an oxide anion. It is of interest to raise at this point that the double Perovskite has seen a vast technological application in such photovoltaic devices [2-6] as electro-optics crystals, electron acoustics, high density optical memories, photo-detectors, solar cells and short wavelength lasers. This has been due to their magnetic and magneto-optical properties. In fact, a handful of these materials' characteristics make the scientific research take more interest in them. These characteristics are: the half-metallicity [7-8]; magneto-dielectricity [9]; high magnetic ordering temperatures [10]; and magneto-resistance [11]. As set out in ref. [12-18], it appears that the employment of the different calculation methods along with the appropriate approximation is of paramount importance to launch thorough-going and in-depth investigation into the Perovskite materials, particularly, into the electronic, magnetic and optical properties of $\mathrm{Ba}_{2} \mathrm{MUO}_{6}$ with $(\mathrm{M}=\mathrm{Ni}, \mathrm{Co}, \mathrm{Cd}$ and $\mathrm{Zn})$.

As an endeavor to complete our understanding of these compounds and its three properties proposed to be under study in this work, it is of uttermost importance to keep in our mind that more attention and importance attached to the study of the electrical and optical properties of double perovskites, as the third property of the compound studied in this work, on the assumption that they are in a better position to revolutionize this branch owing to their application in electronic and optical devices. As illustrated in the last section of this research paper, the optical properties reflect the energy distribution of the electron states in the valence 
and conduction bands. These optical properties spring from the inter-band transitions between B site transition metal cations and Oxygen ions [19-21].

Before restricting further our discussion to how the main and precise point in question in the paper shall be tackled, it is insightful to indicate that the presentation of the structural data $(\mathrm{Co}, \mathrm{Ni}$ and $\mathrm{Cd}, \mathrm{Zn})$ of these compounds are given in these two consecutive references: [23] and [24]. The source of these data is the power X-ray patterns that have been reported in [23-28]. The compound's crystal structures are an undistorted cubic Perovskite composite whom space group is $\mathrm{Fm} \overline{3} m$. As cited by ref. [23], $\mathrm{a}=\mathrm{b}=\mathrm{c}=8.3311 \AA(\mathrm{M}=\mathrm{Ni}), \mathrm{a}=\mathrm{b}=\mathrm{c}=8.3738 \AA$ $(\mathrm{M}=\mathrm{Co}), \mathrm{a}=\mathrm{b}=\mathrm{c}=8.6214 \AA(\mathrm{M}=\mathrm{Cd})$ and $\mathrm{a}=\mathrm{b}=\mathrm{c}=8.3980 \AA(\mathrm{M}=\mathrm{Zn})[24]$ are the compound's parameters[24]. Following in the footsteps of a number of the physicists who have come up with important results and inferences, we are undoubtedly contend that the double Perovskites $\mathrm{Ba}_{2} \mathrm{NiUO}_{6}$ and $\mathrm{Ba}_{2} \mathrm{CoUO}_{6}$ are ferromagnetically orders at 25 and $9.1 \mathrm{~K}$ respectively [23-26]. These results have been shown or proved by both the detailed magnetic susceptibility and specific heat measurements.

Despite all the findings and results attained by the researchers from the different quarters of the globe, it is imperative to bring up the fact that more research is always needed to further and consolidate our knowledge of the component which takes spotlight in this research paper and, from this belief, the aim of our work is formulated and defined accordingly. As referred to above, this aim is particulaly to explore and study more profoundly the electronic, magnetic and optical properties of our compound $\mathrm{Ba}_{2} \mathbf{M U O}_{6}$ with $\mathbf{M}=\mathrm{Ni}, \mathrm{Co}, \mathrm{Zn}$ and $\mathrm{Cd}$ utilizing DFT as a simulation method. The latter is resorted to in the belief that it is indispensable and more feasible here to determine the structural optimization, the stability structure, the density of state, reflectivity, absorbance, etc. The determination and study of the previously-mentioned key words and others dealt with in the paper shall be the point of the interest of our research, because, to our best knowledge, more in-depth examination and contributions are needed to make into this using DFT calculation.

As a step towards detailing constructively and concisely the points stipulated in the abstract and introduction, the organization of the paper takes a three-section form. The first one is for providing the necessary details related to the calculations and the formulae used. Afterwards, the second section headed "Results and Discussion" follows for investigating and interpreting the stability of the structure, band structures, electronic structure and magnetic properties and optical ones. As always, the work is tailed with a recapitulation of the main points brought up along the paper's lines.

\section{2- Calculations details}

To begin with, the calculations have been performed along with the utilization of the Full Potential Linearized Augmented Plane Wave (FP-LAPW) method as used in WIEN2K package [28]. It is interesting to note here that the unit cell of the cubic structure undergoes the process of division in the FP-LAPW method. This division makes the unit cell of the cubic structure consist of two regions. The first one is called an interstitial region and the second one is that of the non-overlapping muffin-tin spheres on the vicinity of the atomic sites. More importantly, the Kohn Sham Equation and the exchange correlation potential are among various basis sets 
that are employed among the two regions mentioned above. Aiming to give more details about the preceding basis sets, suffice it to say that the second basis set is dealt with in the framework of the Generalized Gradient Approximation (GGA) for the total energy calculations while the Kohn Sham equation, whose predication is on the DFT, is solved in a self-consistent scheme [28-29]. The GGA method is used in this work as it presents results very close to experimental results.

Numerically expressed, for the expansion of the muffin-tin spheres, lattice harmonics have been used up to $\mathrm{L}=8$; knowingly that for $\mathbf{B a}, \mathbf{U}$ and $\mathbf{O}$, the muffin-tin radii are assumed to be 2.5, 2.3 and $\mathbf{1 . 7}$ atomic units (a.u) consecutively, and for $\mathrm{M}=\mathrm{Ni}=\mathbf{1 . 5}, \mathbf{M}=\mathbf{C o = 1 . 2}$, $\mathbf{M}=\mathbf{C d}=\mathbf{1 . 4}$ and $\mathbf{M}=\mathbf{Z n}=\mathbf{1 . 6}$. As established in [31], along with the employment of the Monkhorst-Pack special k-points approach, the integrals over the Brillouin zone are performed up to $1000 \mathrm{k}$-points in the Irreducible Brillouin Zone (IBZ for short). Furthermore, the achievement of a satisfactory degree of convergence has been through taking into consideration a number of the FP-LAPW basis functions up to $\mathrm{R}_{\mathrm{MT}} \mathrm{K}_{\max }=8$ where:

- $\quad$ RMT denotes the average radius of the muffin-tin spheres and;

- Kmax signifies the maximal value of the wave vector $K=k+G)$.

To conclude, it is worthwhile noting here that when the total energy of the system is stable within $10^{-5} \mathrm{Ry}$, the self-consistent calculations are to converge.

In consonance with the previous, it is important to contend that $\mathrm{Ba}_{2} \mathbf{M U O}_{6}$ compounds have a cubic symmetry in that the $\mathrm{Ba}$ atom is situated at $(1 / 4,1 / 4,1 / 4)$, the $\mathbf{M}(\mathbf{C d}, \mathbf{N i}, \mathrm{Zn}$ and Co) atoms are located at $(1 / 2,1 / 2,1 / 2)$, the $\mathrm{U}$ is placed at $(0,0,0)$ while the $\mathrm{O}$ atom for $\mathrm{M}=\mathrm{Ni}$ is resided at $(0.2467,0,0)$. For $\mathrm{M}=\mathrm{Co}$ and $\mathrm{M}=\mathrm{Cd}$ are located at $(0.2492,0,0)$ and at $(0.2402,0$, 0 ) respectively, and finally for $\mathrm{M}=\mathrm{Zn}$ is located at $(0.2527,0,0)$ [23-26]. The space group of compounds is $F \mathrm{~m} \overline{3} m$. As presented in figure 1 .

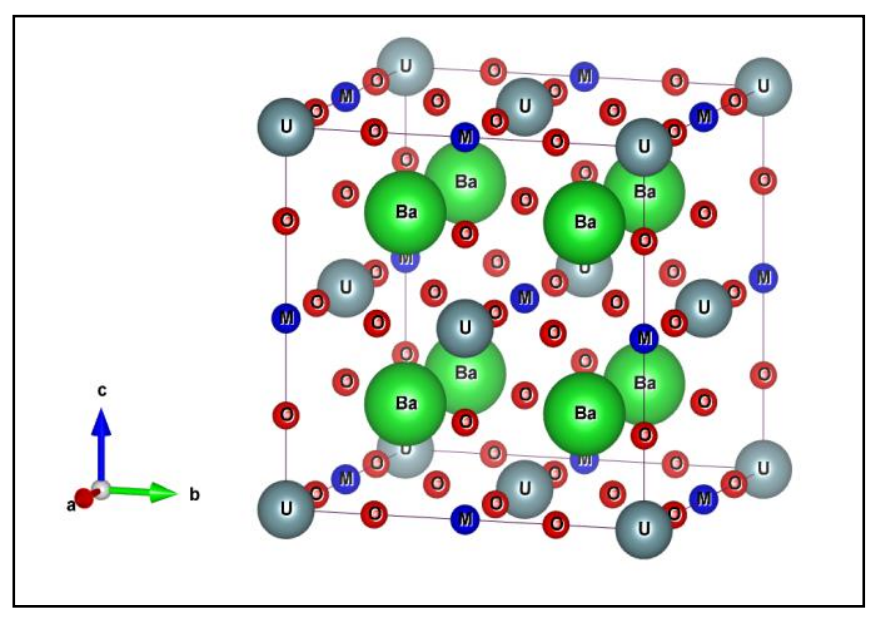

Figure.1 : The structure of the compounds $\mathrm{Ba}_{2} \mathrm{MUO}_{6}$

The study of the other but the complementary side -the optical properties- of our compound is in line. It is worth-saying that along with the formalism of Ehrenreich and Cohen and via the frequency-dependent dielectric function $\varepsilon(\omega)=\varepsilon_{1}(\omega) \_i \varepsilon_{2}(\omega)$, the obtaining of the optical properties can be possible to attain as given by ref. [28]. Thus, the imaginary part of the dielectric function is expressed in this way: 


$$
\boldsymbol{\varepsilon}_{2}(\boldsymbol{\omega})=\left(\frac{\mathrm{h} \mathrm{e}^{2}}{\pi \mathrm{m}^{2} \omega^{2}}\right) \sum_{\mathbf{v}, \mathbf{c}} \int_{\mathrm{BZ}}\left|\mathbf{M}_{\mathrm{Cv})}(\mathbf{K})\right|^{2} \boldsymbol{\delta}\left[\boldsymbol{\omega}_{\mathrm{Cv}}(\mathbf{k})-\boldsymbol{\omega}\right] \mathbf{d}^{3} \mathbf{k}
$$

where the integral signifies over the first $\mathrm{BZ}, \mathrm{h} \omega_{\mathrm{Cv}}(\mathrm{k})=$ Eck-Evk refers to the excitation energy, e denotes the polarization vector of the electric field, $\mathrm{M}_{\mathrm{Cv})}(\mathrm{K})=<\mathrm{u}_{\mathrm{ck}}|\mathrm{e} \nabla| \mathrm{u}_{\mathrm{vk}}>$ designate the dipole matrix elements for the direct transitions between the valence and the conduction band states, and $u_{c k}(r)$ is the periodic part of the Bloch wave function for a conduction band state with the wave vector $\mathrm{k}$.

Additionally important, using the Kramers-Kronig relations, the imaginary part is the source from which the real part of the dielectic function $\varepsilon_{1}(\omega)$ can originate:

$$
\varepsilon \mathbf{1}(\omega)=\mathbf{1}+\frac{2}{\pi} \mathbf{p} \int_{0}^{\infty} \frac{\omega / \varepsilon_{2}\left(\omega^{\prime}\right)}{\omega^{\prime 2}-\omega^{2}} \mathbf{d} \omega^{\prime}
$$

where $\mathrm{P}$ meaning the principal value of the integral.

Going further into the same direction, the calculation of the important optical functions of the system, which is in the spotlight too in the last phase of the following section, cannot be carried out without having determining the two parts of the dielectric function: real and imaginary. The importance of the knowledge of these parts lies in permitting the performance of the calculations of the functions already referred to. From this perspective, it is of great help to mention that the refractive index $\mathbf{n}(\omega)$ has been calculated via this formula [31]:

$$
\mathbf{n}(\omega)=\left(\frac{1}{\sqrt{2}}\right)\left[\sqrt{\varepsilon 1(\omega)^{2}+\varepsilon 2(\omega)^{2}}+\varepsilon 1(\omega)\right]^{1 / 2}
$$

By means of this tool of simulation, different physical quantities are established: the optimal parameters are presented in stability of structures section, the bands structures are treated in the band structure section, the total-partial DOS is presented in electronic structure and magnetic properties section, the absorption spectrum, the optical band gaps and the last parameter in this present work is the transmittance spectra are analyzed in the Optical properties section. Thus, we displayed in the next part the results reached in this current work.

\section{3- Results and discussions}

\subsection{Stability of structures}

As always, employing the WIEN2k package, the structural optimization has been conducted in the framework of the GGA approximation. Simply put, the structural optimization of our compounds is carried out, as Fig. 2 demonstrates, by means of the minimization of the total energy as a function of the volume V. To this effect, the optimization cycle occurring repeatedly till the convergence of energy has been realized, and as a result of this operation, a number of the values produced. These values, which are the optimal ones, are recorded along with the experimental parameters in the following table:

\begin{tabular}{|c|l|c|}
\hline Compounds & & $\begin{array}{c}\text { Compounds } \\
\text { parameters }(\AA)\end{array}$ \\
\hline $\mathrm{Ba}_{2} \mathbf{N i U O}_{6}$ & GGA calculations & 8.2076 \\
\cline { 2 - 3 } & $\begin{array}{l}\text { Experimental } \\
\text { value[23] }\end{array}$ & 8.3311 \\
\hline $\mathrm{Ba}_{2} \mathbf{C o U O}_{6}$ & GGA calculations & 8.2146 \\
\cline { 2 - 3 } & $\begin{array}{l}\text { Experimental } \\
\text { value[23] }\end{array}$ & 8.3738 \\
\hline $\mathrm{Ba}_{2} \mathbf{Z n U O}_{6}$ & GGA calculations & 8.2394 \\
\cline { 2 - 3 } & \multicolumn{2}{|c}{} \\
\hline
\end{tabular}




\begin{tabular}{|l|l|c|}
\cline { 2 - 3 } & $\begin{array}{l}\text { Experimental } \\
\text { value[24] }\end{array}$ & 8.3980 \\
\hline $\mathrm{Ba}_{2} \mathbf{C d U O}_{6}$ & GGA calculations & 8.5294 \\
\cline { 2 - 3 } & $\begin{array}{l}\text { Experimental } \\
\text { value[24] }\end{array}$ & 8.6214 \\
\hline
\end{tabular}

Table 1: The illustration of the optimal values obtained and the experimental ones Comparatively speaking, it is strikingly clear from the table that our values are approximately in agreement with the experimental values of the other works.

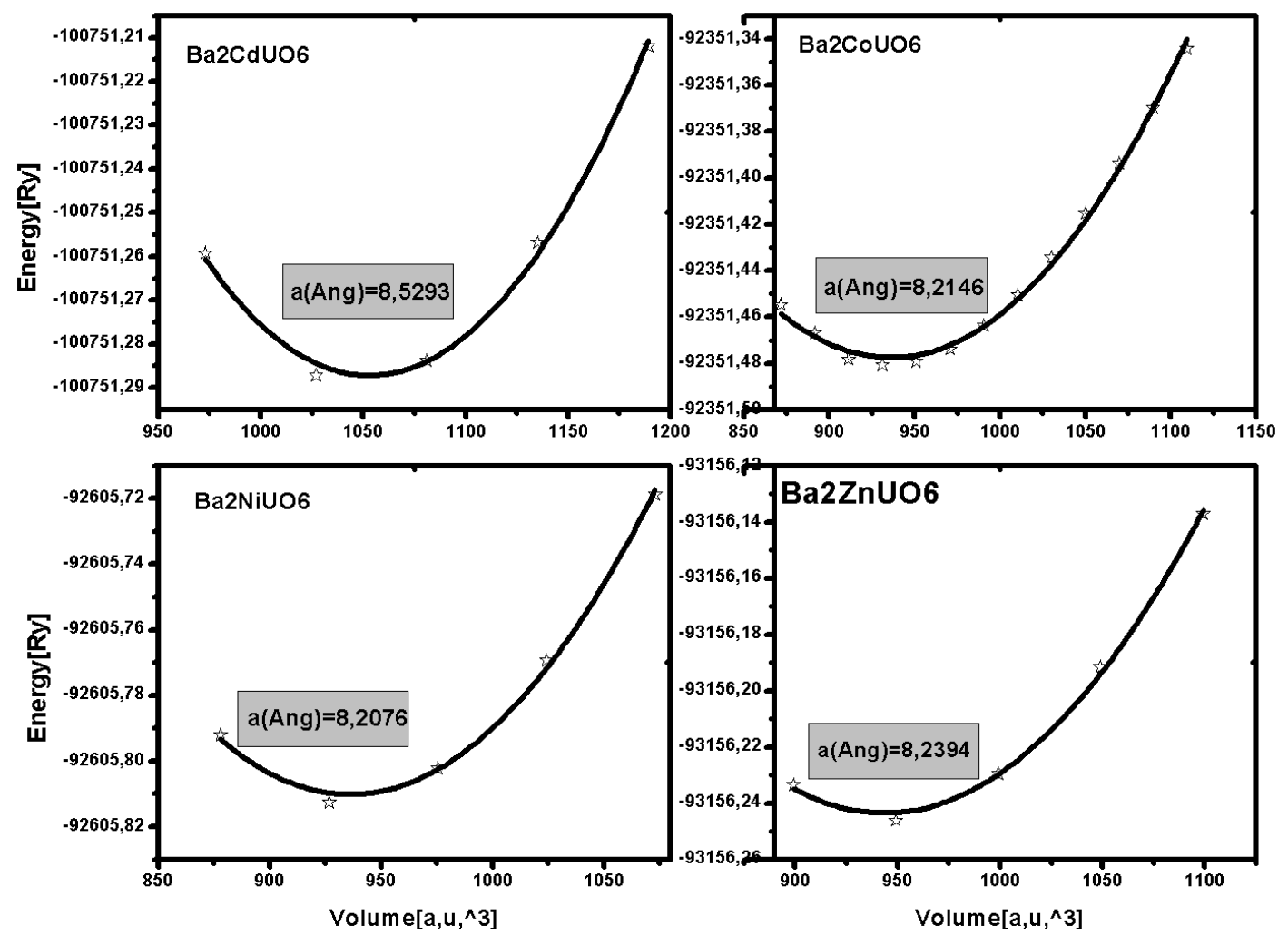

Fig.2: The variation of the total energy as a function of the volume of the $\mathrm{Ba}_{2} \mathrm{MUO}_{6}$ compounds by the approximation (GGA)

\subsection{Bands structures}

Fig. 3, is intended to display the calculated band structure of the $\mathrm{Ba}_{2} \mathbf{M U O}_{6}$ compound with $\mathbf{M}=\mathrm{Ni}, \mathrm{Co}, \mathrm{Cd}$ and $\mathrm{Zn}$. For $\mathrm{M}=\mathrm{Ni}, \mathrm{Cd}$ and $\mathrm{Zn}$, it is observed that the minimal point of the conduction band and the valence band's maximal point are situated at the same vector $(\mathrm{L})$ of Brillouin Zone; hence, it has been deduced that $\mathbf{M}=\mathrm{Ni}, \mathrm{Cd}$ and $\mathrm{Zn}$, having been characterized by a direct, belong to the family of semiconductors. In line with this, the results of the gap energy, whose calculation performed within the first principles based on Density Function Theory (DFT), are $1.37 \mathrm{eV} ; 1.880 \mathrm{eV}$ and 1.603 for $\mathrm{M}=\mathrm{Ni}, \mathrm{M}=\mathrm{Cd}$ and $\mathrm{M}=\mathrm{Zn}$ respectively. It is worth-raising at this stage that the $\mathrm{Ba}_{2} \mathrm{CoUO}_{6}$ compound presents a metallic aspect $(\mathrm{Eg}=0.0 \mathrm{eV})$. 

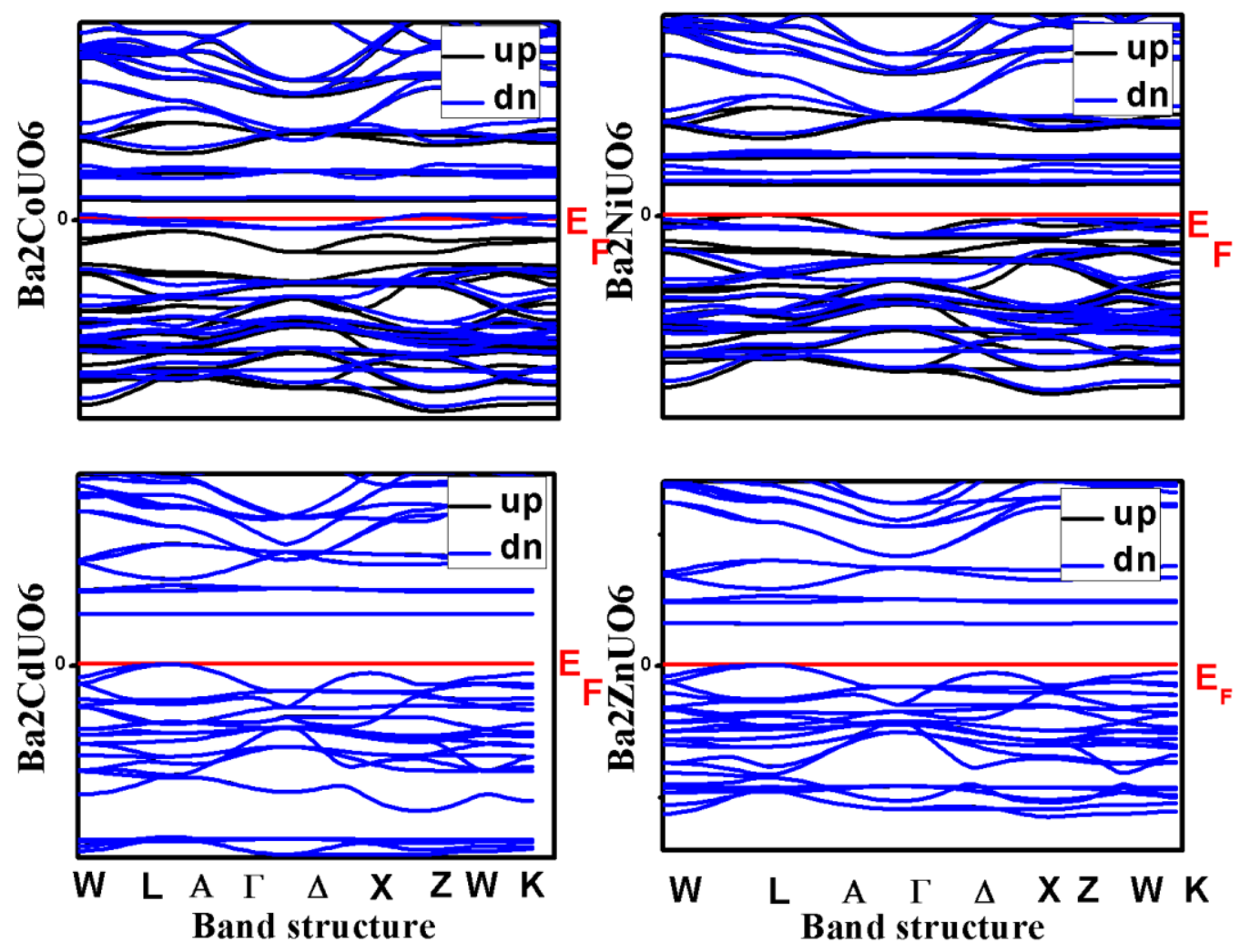

Fig. 3: Bands structures of $\mathrm{Ba}_{2} \mathrm{MUO}_{6}$ with GGA calculation

\subsection{Electronic structure and magnetic properties}

In our calculation, the study of the total and partial densities of states is the concern of this subsection so that we could make more accurate and scientific investigation into the electronic and magnetic structure of $\mathrm{Ba}_{2} \mathrm{MUO}_{6}$ compounds. Following this procedure, not only are we able to determine the source of the magnetic moment which emerges in the case of $\mathrm{Ba}_{2} \mathrm{CoUO}_{6}$ and $\mathrm{Ba}_{2} \mathrm{NiUO}_{6}$, but also to explore and investigate the appearance of the band gaps energy for the case of $\mathrm{M}=\mathrm{Ni}, \mathrm{Zn}, \mathrm{Cd}$. This is what the following figure aims to demonstrate: 

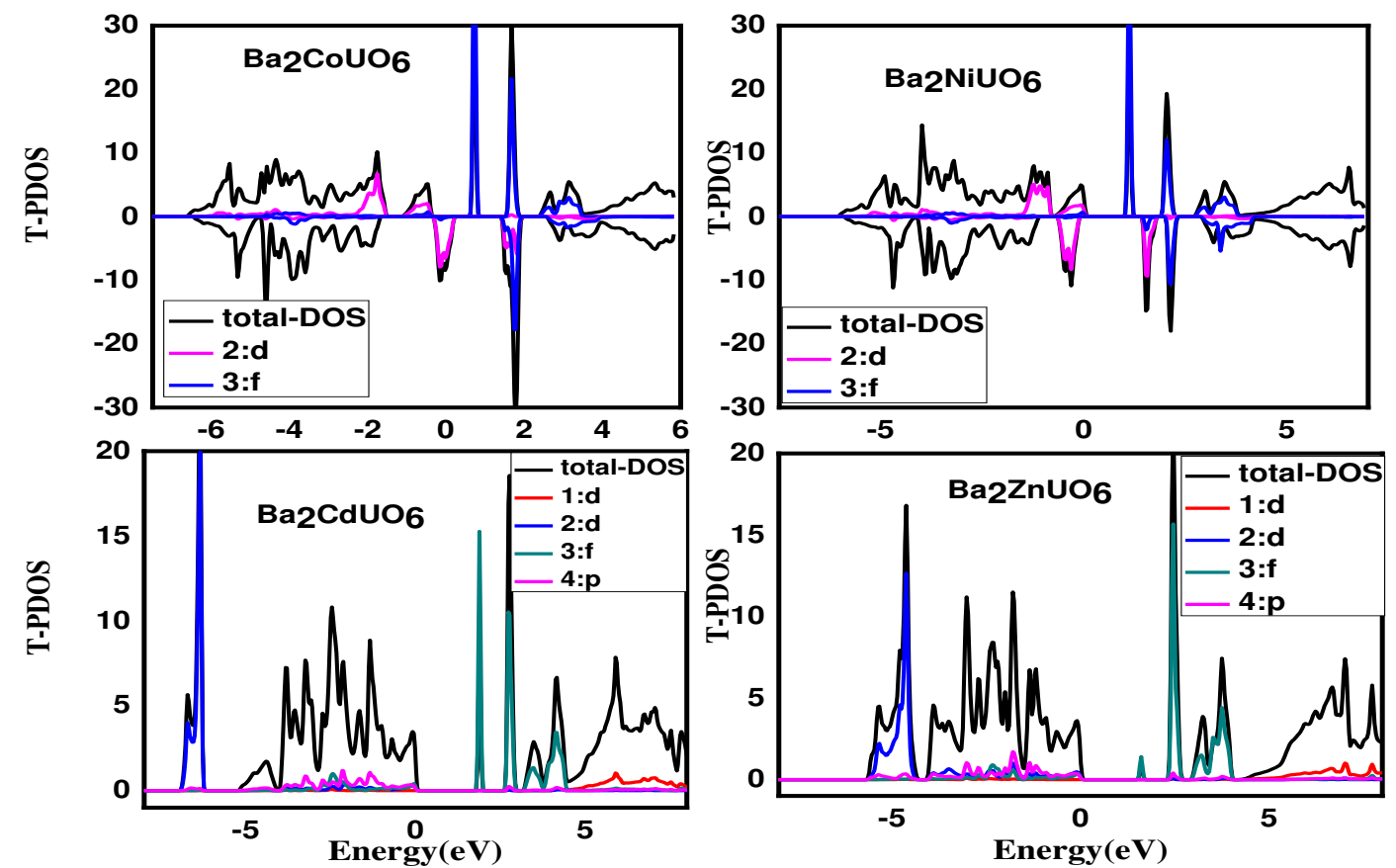

Fig. 4: The total and partial densities of states of the $\mathrm{Ba}_{2} \mathrm{MUO}_{6}$ compounds with $\mathrm{M}=$ $\mathrm{Co}, \mathrm{Ni}, \mathrm{Cd}$ and $\mathrm{Zn}$

As it can be clearly observed from within this figure, which displays the total and partial densities of the states of $\mathrm{Ba}_{2} \mathbf{M U O}_{6}$ compounds, a host of interesting inferences can be made. First, we can point out that for the case of $\mathrm{Ba}_{2} \mathrm{CoUO}_{6}$ and $\mathrm{Ba}_{2} \mathrm{NiUO}_{6}$, the valence band primarily consists of the d-states of $\mathrm{Co}$ and $\mathrm{Cd}$ while the conduction band is essentially composed of the f-states of $\mathrm{U}$. Second, the $\mathrm{Ba}_{2} \mathrm{CoUO}_{6}$ compound presents a metallic aspect that is mainly due to the d-states of Co which is placed around Fermi level. From this, we can remark the presence of a slight difference between the substitution of $\mathrm{Co}$ and Ni. Third, the band gap for $\mathrm{Ba}_{2} \mathrm{NiUO}_{6}$ emerges because of the transfers load between the d-states of $\mathrm{Ni}$ and the f-states of $\mathrm{U}$.

More closely associated, for the $\mathrm{Ba}_{2} \mathrm{CdUO}_{6}$ and $\mathrm{Ba}_{2} \mathrm{ZnUO}_{6}$ compounds, the valence band is formed essentially by the d-states of $\mathrm{Cd}, \mathrm{Zn}$ and $\mathrm{p}$ - states of oxygen whereas the f-states of $\mathrm{U}$ and d-ones of $\mathrm{Ba}$ constitute particularly the conduction band. In this phase, it is highly important to underscore that the appearance or emergence of a gaps energy for $\mathrm{M}=\mathrm{Cd}, \mathrm{Zn}$ could be attributed to the transfer load between the p-states of Oxygen and f-states. The values of the gaps determined are equal to $1.88 \mathrm{eV}$ for $\mathrm{Cd}$ and $1.603 \mathrm{eV}$ for $\mathrm{Zn}$ respectively. These compounds, $\mathrm{M}=\mathrm{Cd}$ and $\mathrm{M}=\mathrm{Zn}$, are semiconductors with the direct gap and also they aren't magnetic, because of the symmetry of the spin states up and spin states down. That significates, the difference between these densities of states, up and down, are null.

In the same vein, for $\mathrm{Ba}_{2} \mathrm{CoUO}_{6}$ and $\mathrm{Ba}_{2} \mathrm{NiUO}_{6}$, as Fig. 4 illustrates, we come to these three following remarks:

- As opposed to $\mathrm{Ba}_{2} \mathrm{CdUO}_{6}$ and $\mathrm{Ba}_{2} \mathrm{ZnUO}_{6}$, these compounds are magnetic, because of the non-symmetry of the spin states up and spin states down. That is, the difference between these densities of states, up and down, is not null;

- They cannot be characterized as half-metal from the very fact that the compounds are magnetic semiconductors, because of the absence of any peak whatsoever at the Fermi level; 
- The exchange coupling $\mathrm{p}-\mathrm{d}$, as the final remark here, is responsible for the magnetism observed in these compounds, due to the hybridization that exists between the oxygen layer $\mathrm{p}$ and the nickel layer $\mathrm{d}$.

Analyzing numerically these remarks with respect to $\mathrm{Ba}_{2} \mathrm{CoUO}_{6}$ and $\mathrm{Ba}_{2} \mathrm{NiUO}_{6}$, the following table clearly exhibits that at the moment when the concentration of the large part of the magnetic moment occurs in the atoms of nickel and cobalt, the Oxygen, the Uranium and the Barium atoms are the refuge that the remaining part takes. This latter part is nearly negligible or null. It is obvious from the table that the total magnetic moment value attained by GGA is very close to the experimental result.

\begin{tabular}{|c|c|}
\hline Atoms & Magnetic values $\left(\mu_{B}\right)$ \\
\hline $\mathrm{Ba}$ & -0.0021 \\
\hline $\mathrm{Ni}$ & 1.5074 \\
\hline $\mathrm{U}$ & 0.1738 \\
\hline $\mathrm{O}$ & 0.0534 \\
\hline Total magnetic moment via GGA & 1.9975 \\
\hline $\mathrm{Experimental} \mathrm{value} \mathrm{of} \mathrm{the} \mathrm{total} \mathrm{magnetic}$ \\
moment & 2.1 \\
\hline $\mathrm{Ba}$ & -0.00241 \\
\hline $\mathrm{Co}$ & 2.49869 \\
\hline $\mathrm{U}$ & 0.18340 \\
\hline $\mathrm{O}$ & 0.05066 \\
\hline Experimental value of the total magnetic \\
moment & 2.99999 \\
\hline
\end{tabular}

Table 2: Magnetic moment values of all the atomic sites and the total magnetic moment.

For the determining the magnetic configuration of these compounds $(\mathrm{M}=\mathrm{Co}$ and $\mathrm{M}=\mathrm{Ni})$, We do the calculation of the total energy of each configuration (FM and AFM), employing the GGA approximation as presented in the table below:

\begin{tabular}{lcc}
\hline Elements & $\mathrm{E}(\mathrm{FM})(\mathrm{eV})$ & $\mathrm{E}(\mathrm{AFM})(\mathrm{eV})$ \\
\hline $\mathrm{M}=\mathrm{Co}$ & -92351.48265771 & -92351.48026631 \\
\hline $\mathrm{M}=\mathrm{Ni}$ & -92605.81344015 & -92605.81103398 \\
\hline
\end{tabular}

Table 3: Total energy for different configurations

According to table 3, we see for $\mathrm{M}=\mathrm{Co}$, Ni that the total energies of the ferromagnetic state are minimal. That is, more stable compared to the energies of antiferromagnetic state so they are stable in the ferromagnetic state. 


\section{3-4 Optical properties}

This component of this research paper looks at the calculation of the Absorption coefficient. However, before embarking on detailing this point through treating the absorption spectrum, the optical band gaps and the optical transmittance spectra to understand the optical behavior, it is highly interesting to underline that the absorption coefficient is a parameter that can show the characteristic and absorption behavior of a material to absorb the energy that penetrates it. This absorption, which can be extracted from the attenuation of energy, depends most on the dielectric function. Thus, the dielectric function is given in the following equation and can be written as follows:

$$
\varepsilon(\omega)=\varepsilon_{1}(\omega)+i \varepsilon_{2}(\omega)=N^{2}
$$

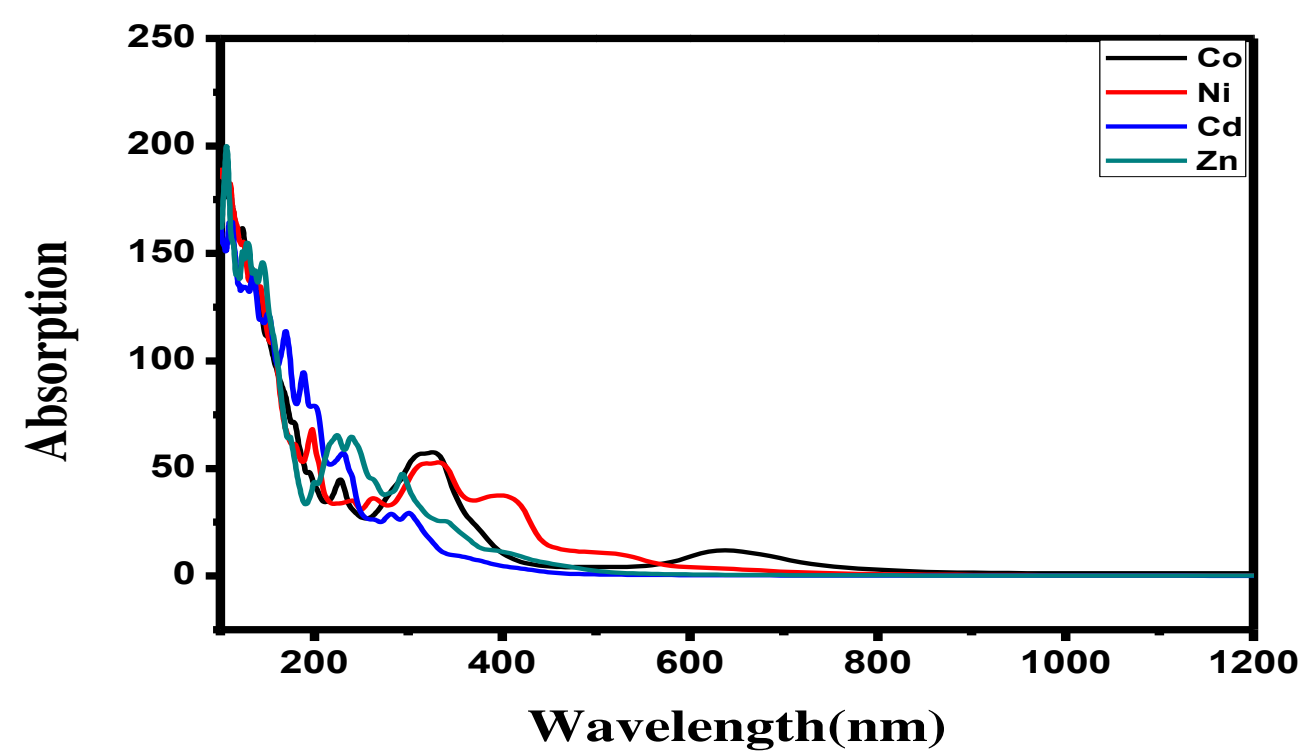

Fig. 5: The absorption spectrum of $\mathrm{Ba}_{2} \mathrm{MUO}_{6}$ compounds with $\mathrm{M}=\mathrm{Co}, \mathrm{Ni}, \mathrm{Cd}, \mathrm{Zn}$

In our attempt to understand, as mentioned above, the optical behavior of $\mathrm{Ba}_{2} \mathrm{MUO}_{6}$, we study the absorption spectrum (see Fig. 5 above), the optical band gaps and the optical transmittance spectra (figs. 6 and 7) in succession. In this regard, DFT calculation shows the optical parameters and its variation which is subject to the substitution of the position of $\mathrm{M}$ in the unit cell of the $\mathrm{Ba}_{2} \mathrm{MUO}_{6}$ compounds. Seen in this light, we can deduce from Fig. 5 that the absorption is monumentally important in the ultraviolet sphere and becomes very weak in the visible light range. Most importantly too, from $\lambda=400 \mathrm{~nm}$, the $\mathrm{Ba}_{2} \mathrm{CdUO}_{6}$ and $\mathrm{Ba}_{2} \mathrm{ZnUO}_{6}$ materials are considered non-absorbent, and this is due to the existence of $\mathrm{Zn}$ and $\mathrm{Cd}$. Nonetheless, no radiation is absorbed or scattered. For the case of $\mathrm{Ba}_{2} \mathrm{CoUO}_{6}$ and $\mathrm{Ba}_{2} \mathrm{NiUO}_{6}$, it is noted that a small quantity of light is absorbed, especially from $300 \mathrm{~nm}$ to $750 \mathrm{~nm}$, and the existence of $\mathrm{Co}$ and $\mathrm{Ni}$ introduces interaction and inter-bands transition. This leads to the absorption of energy.

Based on the absorption coefficient, the optical band gap can be extracted by the following relationship:

$$
(\alpha \hat{h} v)^{m}=A(\mathrm{~h} v-\mathrm{Eg})
$$

where $\mathrm{m}$ can take 2 for the direct gap and $1 / 2$ for the indirect gap. Also, we note that $\mathrm{A}$ is a constant which depends on the possible transition that exists. The absorption coefficient is used to calculate the band energies with plotting $(\alpha f v)^{m}$ versus $(h v)$.It is observed that with the 
linear extrapolation of $\alpha$ to zero, we can find the optical band values which are marked in Fig. 6. The gap is direct and the values are found equal to $1.3 \mathrm{ev}, 1.7 \mathrm{ev}, 2.02 \mathrm{ev}$ for $\mathrm{Ni}, \mathrm{Zn}$ and $\mathrm{Cd}$ respectively.

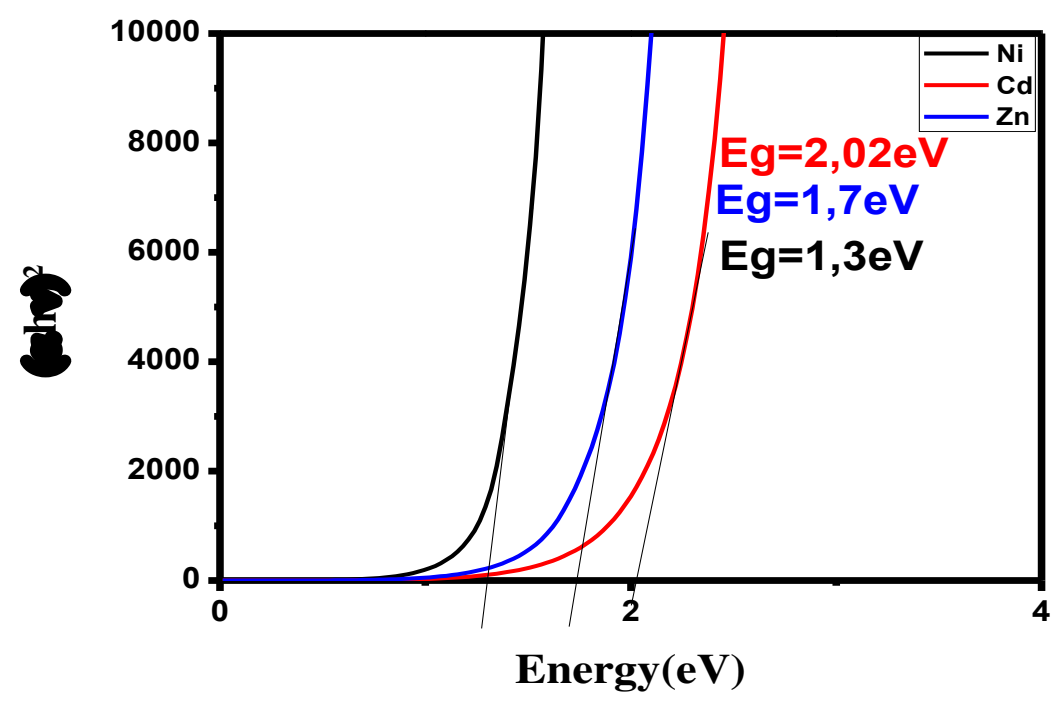

Fig. 6: The different optical band gaps of $\mathrm{Ba}_{2} \mathrm{MUO}_{6}$

Fig. 7 illustrates, in its turn, the variation of the transmittance depending on the wavelength. In straightforward words, our calculations show that the transmittance is higher for the case of $\mathrm{Ba}_{2} \mathrm{CdUO}_{6}$ and $\mathrm{Ba}_{2} \mathrm{ZnUO}_{6}$ therefore, they can be considered as transparent materials in the visible light range. Unlike the case of $\mathrm{Ba}_{2} \mathrm{CoUO}_{6}$ and $\mathrm{Ba}_{2} \mathrm{NiUO}_{6}$, the calculations highlight the fact that the transparency is low and unstable. This instability and lack of transparency are due to the absorption of a significant quantity of energy, especially at $\lambda=450$ for $\mathrm{M}=\mathrm{Co}$, and $\lambda=300 \mathrm{~nm}$ for $\mathrm{M}=\mathrm{Ni}$. To elucidate more, Table 3 just below and the following figure 7. manifest the average of transmittance of $\mathrm{Ba}_{2} \mathrm{MUO}_{6}$ in some detail and numerically.

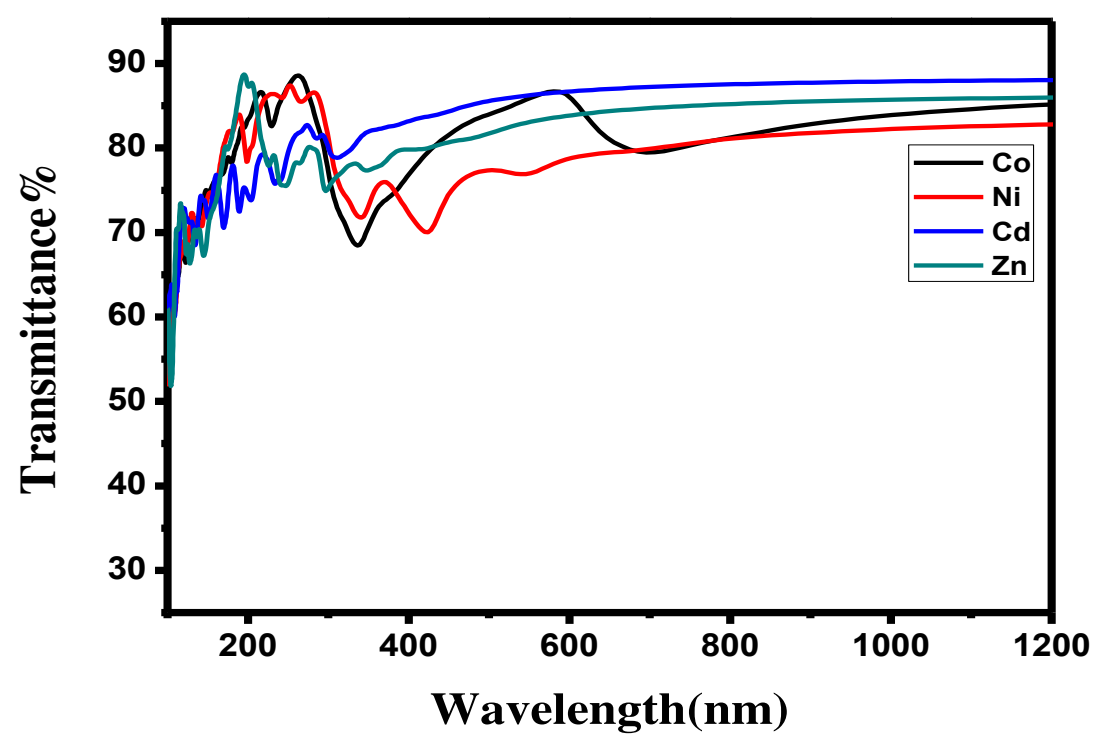

Fig. 7: The transmittance spectra of $\mathrm{Ba}_{2} \mathrm{MUO}_{6}$ compounds

As just indicated, the following table clarifies the different average transmittance for each substitution of the position $\mathrm{M}$. The main results that are worth-recording are very briefly: Cadmium and Zinc are more efficient and favorable for better transparency materials, while Co and $\mathrm{Ni}$ have low values. 


\begin{tabular}{ll}
\hline Elements & Visible light \\
\hline Co & $80 \%$ (unstable) \\
Ni & $79 \%$ \\
Cd & $88 \%$ \\
Zn & $84 \%$ \\
\hline
\end{tabular}

Table 4: The averages of transmittance of $\mathrm{Ba}_{2} \mathrm{MUO}_{6}$ compounds

\section{4- Conclusion}

We have dedicated our time and efforts, throughout this work, to studying and exploring the electronic, magnetic and optical properties of the Double Perovskites $\mathrm{Ba}_{2} \mathbf{M U O} \mathrm{O}_{6}$ with $(\mathbf{M}=\mathrm{Ni}, \mathrm{Co}, \mathrm{Cd}, \mathrm{Zn})$. We made some contributions into this scientific area. By using the Generalized Gradient Approximation (GGA) as implemented in the Wien2k package, we have resorted to DFT calculation to deepen our study of the three properties. Via this tool of simulation, different physical quantities are established: the optimal parameters are determined; the band gaps for the case of $\mathrm{M}=\mathrm{Cd}, \mathrm{Zn}, \mathrm{Ni}$, they are having a direct gap and for the case of $\mathrm{M}=\mathrm{Co}$, it is having a metallic aspect $(\mathrm{Eg}=0.0 \mathrm{eV})$. From the DOS, we are determined that for the case of $\mathrm{M}=\mathrm{Cd}, \mathrm{Zn}$, they haven't the magnetic characterization while for the case of $\mathrm{M}=\mathrm{Co}$, $\mathrm{Ni}$, they have the magnetic characterization and also are stable in ferromagnetic state. As a complementary and integral part of our investigation, the optical properties have been examined and explored. we are determined the optical band values which are $1.3 \mathrm{ev}, 1.7 \mathrm{ev}, 2.02 \mathrm{ev}$ for $\mathrm{Ni}$, $\mathrm{Zn}$ and $\mathrm{Cd}$ respectively and that $\mathrm{Ba}_{2} \mathrm{CdUO}_{6}$ and $\mathrm{Ba}_{2} \mathrm{ZnUO}_{6}$ are very transparent with the high average of transmittance (80\%). At the end, the results as such derive their importance from the belief that they are very exploitable and applicable in the solar cell application as transparent electrode devices.

\section{Aknowldgements}

Many thanks go to Mr P.Blaha and Mr K.schwarz for giving us their permission to use in our research paper the WIEN2k code without which the work cannot be brought into being.

\section{References}

[1] H. Ohno, Science 281 (1998) 951.

[2] Q. Li, X. Gong, C. Wang, J. Wang, K. Ip, S. Hark, Adv. Mater. 16 (2004) 1436.

[3] Wilayat Khan, Souraya Goumri-Said, Journal of Magnetism and Magnetic Materials,432, (2017)574-580

[4] Sikander Azam, Saleem Ayaz Khan, Haleem Ud Din, Rabah Khenata, Souraya GoumriSaid,Journal of Magnetism and Magnetic Materials, 413(2016) 57-64

[5] Sikander Azam et al, Semicond. Sci. Technol. 30(2015) 105018.

[6] Nguyen Hoa Hong, Mohammed Benali Kanoun, Jang-Gun Kim, Timur Sh. Atabaev, Kensuke Konishi, Satoshi Noguchi, Makio Kurisu, and Souraya Goumri-Said The Journal of Physical Chemistry C 2018122 (5), 2983-2989

[7] B. Garcia-Landa, C. Ritter, M.R. Ibarra, J. Blasco, P.A. Algarabel, R. Mahendiran, J.Garcia, Solid State Commun. 110 (1999) 435. 
[8] K.I. Kobayashi, T. Kimura, H. Saeada, K. Tekura, Y. Tokura, Nature ,395 (1988) 677.

[9] C. Zhong, J. Fang, Q. Jiang, J. Phys.: Condens. Matter, 16 (2005) 9059.

[10] S. Jin, T.H. Teifel, M. McCormack, R.A. Fastacht, R. Ramesh, L.H. Chen, Science ,254 (1994) 413.

[11] M. Arejdal, L. Bahmad, A. Abbassi, A. Benyoussef,Physica A ,437 (2015) 375-382

[12] M. Arejdal, A. Kadiri, A. Abbassi, et al. J Supercond Nov Magn 29, 2659-2667 (2016).

[13] D.P. Rai, A. Shankar, M.P. Ghimire, Sandeep , R.K. Thapa, Computational Materials

Science ,101 (2015) 13-320

[14] Shuai Zhao, Chunfeng Lan, Jie Ma, Shyam S. Pandey, Shuzi Hayase, Tingli Ma ,Solid

State Communications 213 (2015) 19-23

[15] M. El Yadaria, L. Bahmad, A. El Kenz, A. Benyoussef, Journal of alloys compounds 579 (2013) 86-91

[16] H. Labrim, A. Jabar, A. Belhaj, S. Ziti, L. Bahmad, L. Laânab, A. Benyoussef, Journal of alloys compounds ,641 (2015) 37-42

[17] M. Musa Saad H.-E.a,n, Mohamed Anwar K. Abdelhalim, A. El-Taher, Materials science in semiconductor Processing 34 (2015) 281-290

[18] Alo Dutta, T.P. Sinha Solid state Communications 150 (2015) 1173-1177.

[19] Y.Hinadsu,Y.Doi., J. solid State Chem., 179 (2006) 2079-2085

[20]J.B.Philipp,P.Mjewski,L.Alff,A.Gross,T.Graf,M.S.Brandt,J.Simon,T.Walther,W.Mader,D .Topwal,D.D.Sarma,Phys.Rev. 68 (2003) 144431.

[21] R.Vidya, P.Ravindran, A. Kjekshus, H. Fjellvg, Phys. Rev. 70 (2004) 184414.

[22] S. Baidya, T. Saha-Dasgupta. Phys. Rev. 84 (2011) 035131.

[23] N. G. Chernorukov, A. V. Knyazev, and Z. S. Dashkina, 51 (2009) 101-103.

[24] W.Scharf and H.Weitzel solide state communications, 15 (1974) 1831-1836.

[25] Y.Hinadsu, J. Alloy compd.215 (1994) 161.

[26] Keller ,C. Inorg.chem., 1 (1962) 790.

[27] Irina P. Roof, Mark D. Smith, H.-C.zurLoye. J ChemCrystallogr, 40 (2010) 491-495.

[28] P. Dufek, P. Blaha, et K. Schwarz, « Applications of Engel and Vosko's generalized gradient approximation in solids », Phys. Rev. B, vol. 50 (1994) 7279-7283.

[29] Perdew, Burke, et Ernzerhof, « Generalized Gradient Approximation Made Simple », Phys. Rev. Lett., 77 (1996) 3865-3868.

[30] H. Ehrenreich, M.L. Cohen, Phys. Rev. 115 (1959) 786.

[31] Sonali Saha, T.P. Sinha, Abhijit Mookerjee, Phys. Rev. 62 (2000) 8828. 
Figures

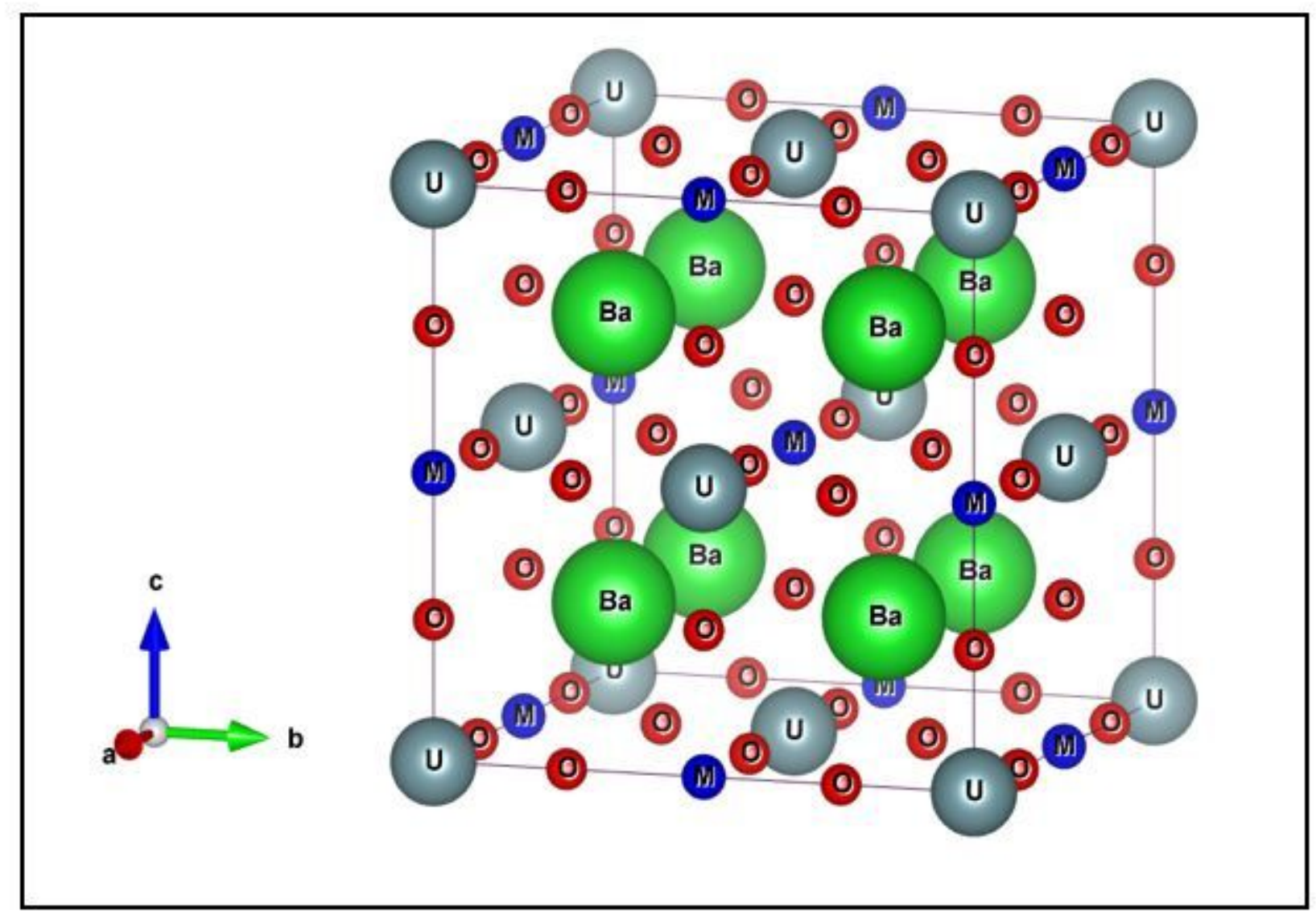

Figure 1

The structure of the compounds Ba2MUO6 

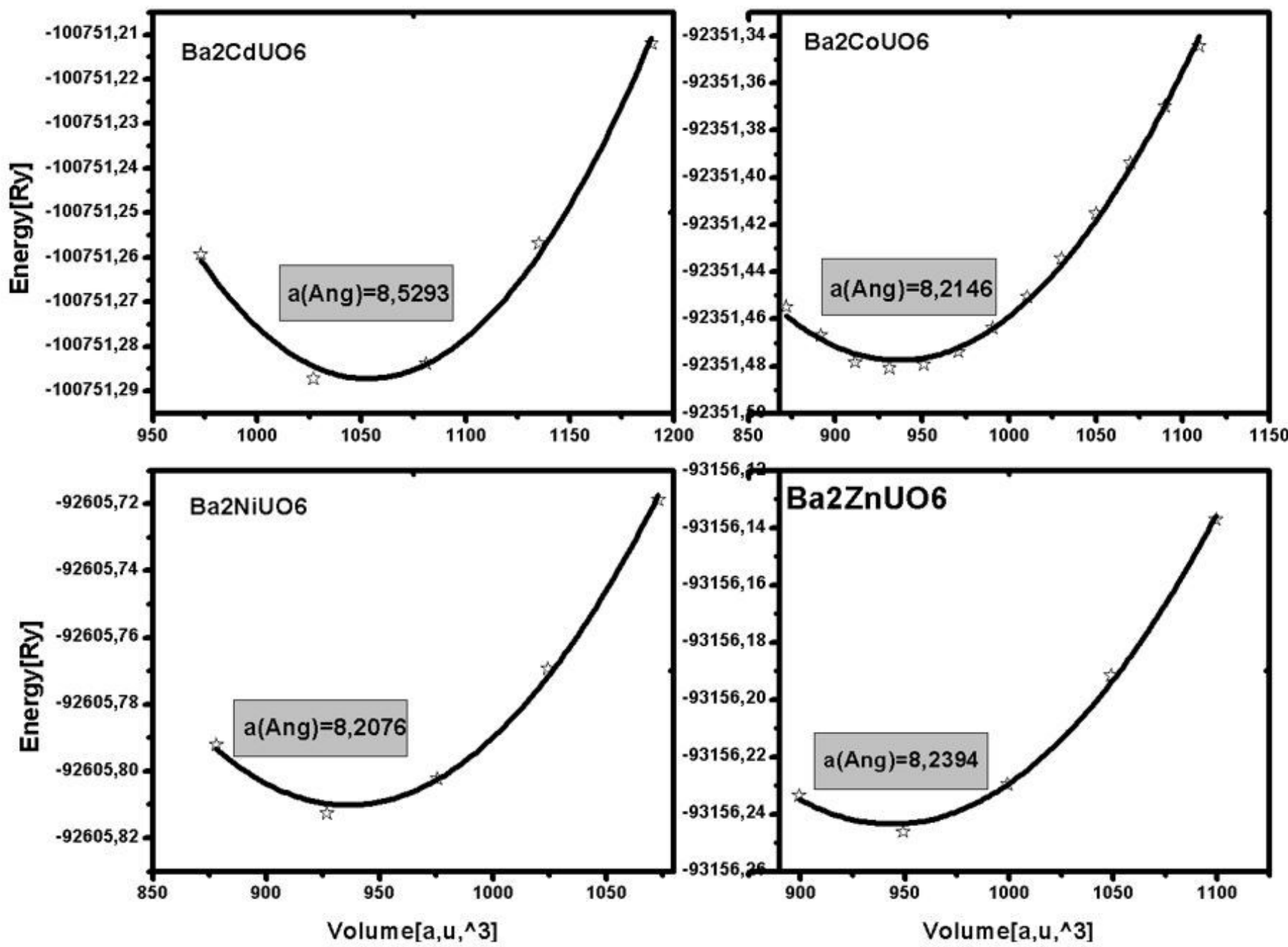

Figure 2

The variation of the total energy as a function of the volume of the Ba2MUO6 compounds by the approximation (GGA) 

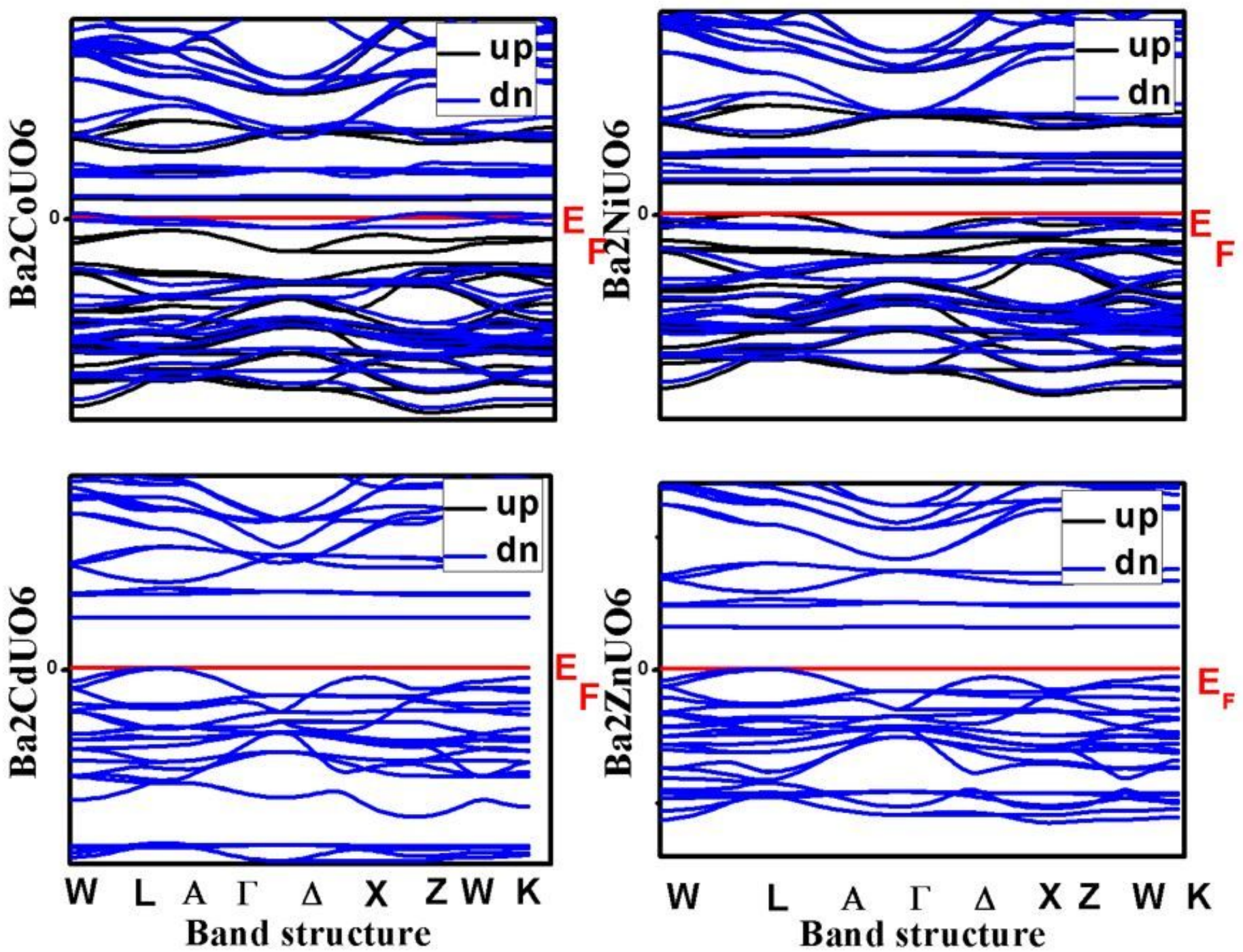

Figure 3

Bands structures of Ba2MUO6 with GGA calculation 

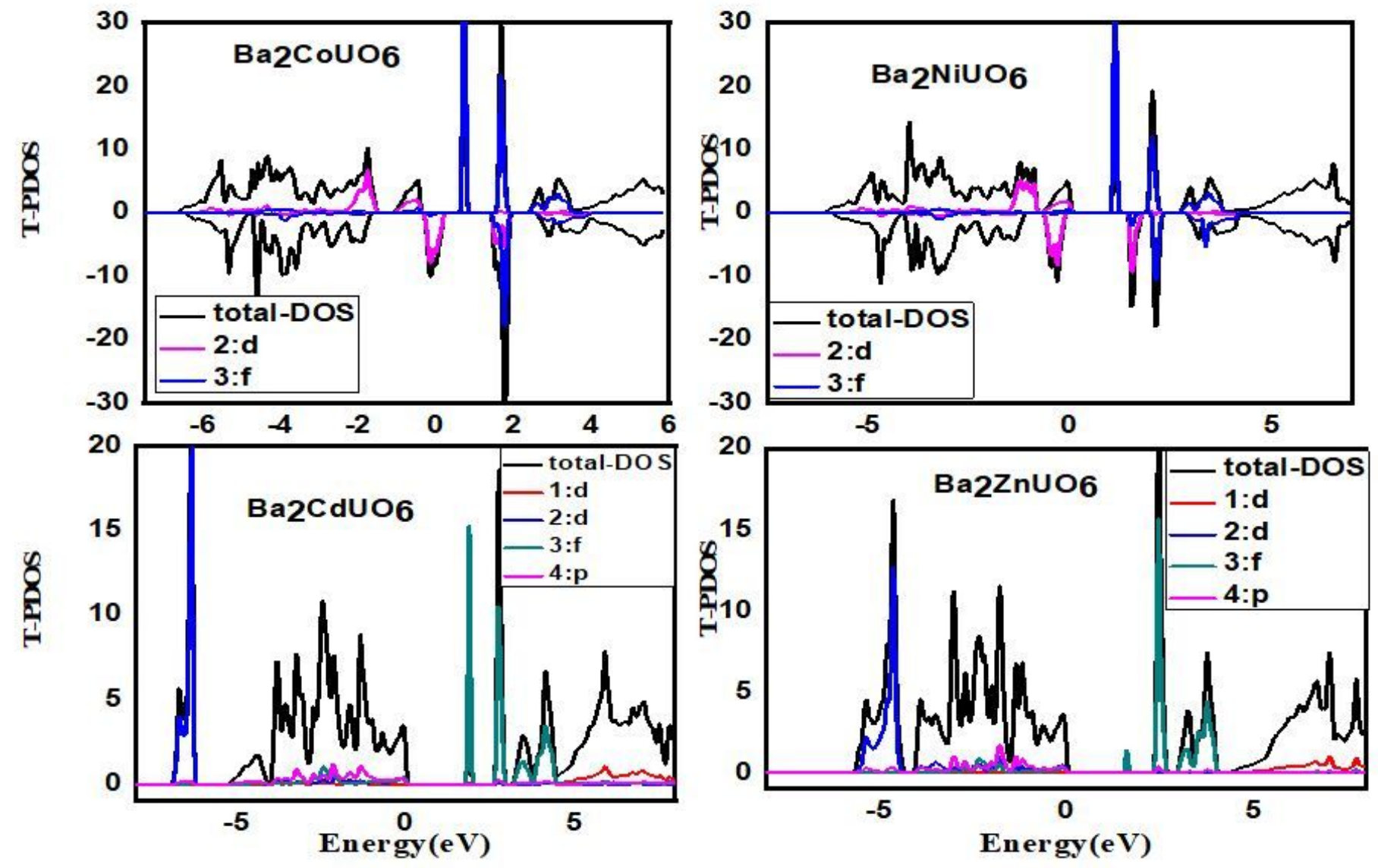

Figure 4

The total and partial densities of states of the Ba2MUO6 compounds with $\mathrm{M}=\mathrm{Co}, \mathrm{Ni}, \mathrm{Cd}$ and $\mathrm{Zn}$ 


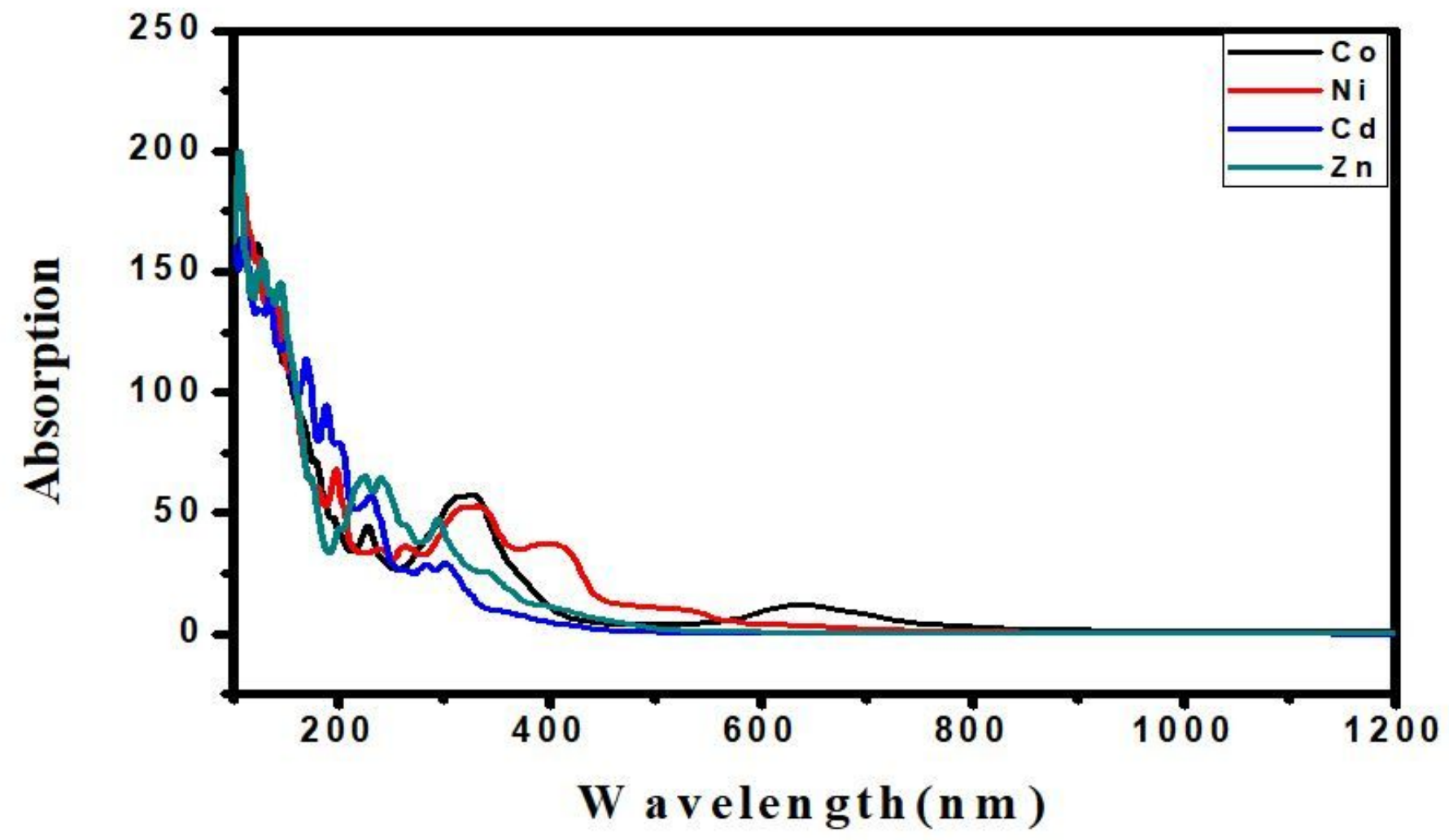

Figure 5

The absorption spectrum of Ba2MUO6 compounds with $\mathrm{M}=\mathrm{Co}, \mathrm{Ni}, \mathrm{Cd}, \mathrm{Zn}$ 


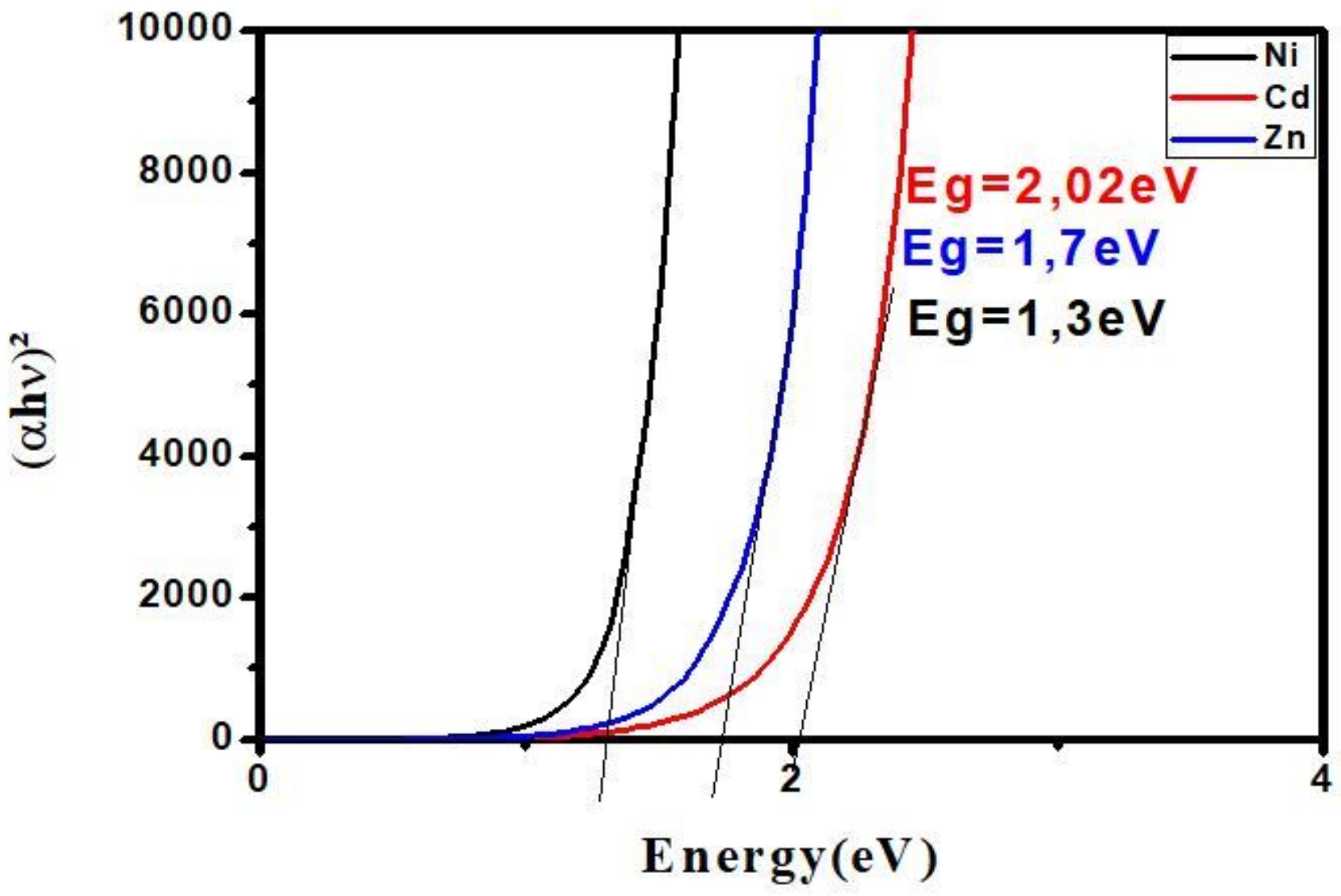

Figure 6

The different optical band gaps of $\mathrm{Ba} 2 \mathrm{MUO} 6$ 


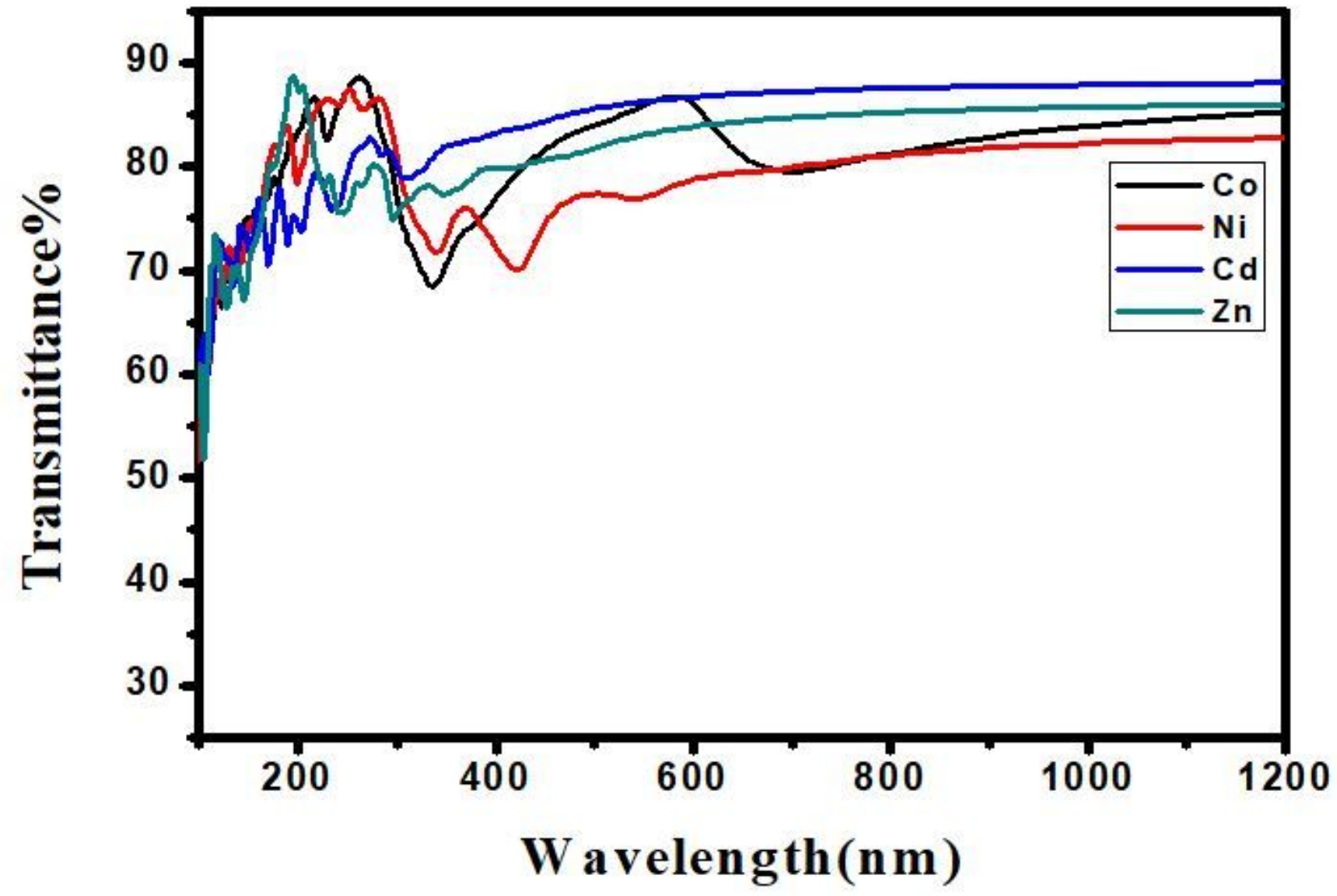

Figure 7

The transmittance spectra of Ba2MUO6 compounds 